\title{
INFEKSI KECACINGAN NEMATODA USUS YANG DITULARKAN MELALUI TANAH (Soil Transmitted Helminth) PADA PETANI SAYUR SAWI HIJAU DI DESA BUG-BUG KECAMATAN LINGSAR KABUPATEN LOMBOK BARAT
}

\author{
Ni Kadek Ayu Parweni ${ }^{1}$, I Wayan Getas ${ }^{2}$, Siti Zaetun ${ }^{3}$ \\ ${ }^{1-3}$ Jurusan Analis Kesehatan, Poltekkes Kemenkes Mataram, Indonesia
}

\section{Article Info}

Article history:

Received Jul $9^{\text {th }}, 2018$

Revised Aug 6 ${ }^{\text {th }}, 2018$

Accepted Sept $17^{\text {th }}, 2018$

Keyword:

Intestinals nematode Soil Transmitted Helminth Infection

\begin{abstract}
Soil transmitted helminth infection can occur at any age. Helminthiasis infections can lead to a decrease of health, nutrition, intelligence and patient productivity to the disadvantage of reducing the quality of human resources. Job is one of the factors that can increase the frequency of helminthiasis infections, especially landrelated work, one of the occupational professions is farmers. The purpose of this reasearch was to determine the description of intestinals nematode infections (Soil Transmitted Helminth) in green mustard farmers in Bug-Bug Village, Lingsar District, West Lombok Regency. This research is descriptive observation using 28 samples of green mustard farmers taken using purposive sampling technique and examined using the direct method with $2 \%$ Eosin dye solution. From the research carried out with 28 samples, it was found that 2 farmers of green mustard were positively infected with intestinals nematode species Trichuris trichiura. The conclusion of this research is the percentage of green mustard farmers that are positively infected with Soil Transmitted Helminth intestinal nematode is 7.14\%. Infection caused by Soil Transmitted Helminth species of Trichuris trichiura.
\end{abstract}

\section{ABSTRAK}

Infeksi kecacingan dapat terjadi pada semua umur. Penyakit kecacingan dapat mengakibatkan menurunnya kondisi kesehatan, gizi, kecerdasan dan produktivitas penderita hingga kerugian yaitu menurunkan kualitas sumber daya manusia. Pekerjaan merupakan salah satu faktor yang dapat meningkatkan frekuensi infeksi kecacingan, terutama pekerjaan yang berhubungan dengan tanah, salah satu profesi pekerjaan tersebut adalah petani. Tujuan dari penelitian ini adalah untuk mengetahui gambaran infeksi kecacingan nematode usus yang ditularkan melalui tanah ( Soil Transmitted Helminth ) pada petani sayur sawi hijau di Desa Bugbug Kecamatan Lingsar Kabupaten Lombok Barat. Penelitian ini bersifat observasi deskriptif menggunakan 28 sampel petani sayur sawi hijau yang diambil menggunakan teknik purposive sampling kemudian diperiksa menggunakan metode langsung dengan larutan pewarna Eosin $2 \%$. Dari penelitian yang telah dilakukian dengan 28 sampel adalah ditemukan 2 orang petani sayur sawi hijau positif terinfeksi kecacingan spesies Trichuris trichiura. Kesimpulan dari penelitian ini yaitu persentase petani sayur sawi hijau yang positif terinfeksi kecacingan nematode usus yang ditularkan melalui tanah ( Soil Transmitted Helminth) adalah $7,14 \%$. Infeksi disebabkan oleh nematode usus yang ditularkan melalui tanah ( Soil Transmitted Helminth ) spesies Trichuris trichiura.

Kata kunci : Nematode usus; Soil Transmitted Helminth 


\section{Pendahuluan}

Infeksi kecacingan dapat terjadi pada semua umur, baik pada balita, anak-anak ataupun orang dewasa. Penyakit kecacingan dapat mengakibatkan menurunnya kondisi kesehatan, gizi, kecerdasan dan produktivitas penderita sehingga banyak menyebabkan kerugian termasuk menurunkan kualitas sumber daya manusia (Safar, 2009).

Tinggi rendahnya frekuensi tingkat kecacingan berhubungan dengan kebersihan diri dan sanitasi lingkungan yang menjadi sumber infeksi. Nematoda usus merupakan kelompok yang sangat penting bagi masyarakat Indonesia karena masih banyak yang mengidap cacing ini sehubungan banyaknya faktor yang menunjang untuk hidup suburnya cacing parasiter ini. Faktor penunjang ini antara lain keadaan alam serta iklim, sosial ekonomi, pendidikan, kepadatan penduduk serta masih berkembangnya kebiasaan yang kurang baik ( Akhsin Zulkoni, 2010).

Faktor pekerjaan juga dapat mempengaruhi frekuensi penyakit parasitik yaitu cacingan, terutama pekerjaan yang berhubungan atau menggunakan tanah. Pekerja yang selalu kontak langsung dengan tanah salah satunya adalah pekerja kebun atau petani sayur yang mempunyai risiko tinggi terinfeksi penyakit menular ini (Ali dkk, 2016). Menurut data Badan Pusat Statistik Kabupaten Lombok Barat tahun 2016 hasil Susenas 2014 sebanyak 27,24\% penduduk Kabupaten Lombok Barat bekerja sebagai petani. Salah satu kecamatan yang termasuk dalam Kabupaten Lombok Barat adalah Kecamatan Lingsar dengan luas tanah 96,58 km2 dan sebanyak 18,49 km2 digunakan sebagai lahan sawah pertanian (BPN NTB, 2016).

Petani adalah satu profesi yang sebagian besar kegiatannya bersentuhan dengan tanah. Hanya sedikit petani yang menggunakan alat pelindung diri seperti sepatu boot atau alas kaki dan sarung tangan saat bekerja, sehingga petani yang tidak menggunakan alat pelindung diri akan langsung bersentuhan dengan tanah dan mendapat infeksi lebih dari 70\% (Salim, 2013).

Petani sayur sawi hijau adalah seorang yang bekerja di bidang pertanian dengan memanfaatkan lahan untuk ditanami tumbuhan sawi hijau dan selalu berkontak langsung dengan tanah. Petani sayur sawi hijau yang menggunakan pupuk kandang sebagai pupuk untuk sayuran sangat berperan penting dalam penyebaran infeksi kecacingan. Petani sayur sawi hijau dapat terinfeksi baik melalui oral yaitu melalui makanan dan minuman yang tercemar dan melalui penetrasi kulit dengan adanya kontak langsung dengan tanah dan kotoran hewan yang digunakan sebagai pupuk tanaman. Tanah dan kotoran hewan yang digunakan sebagai pupuk mengandung telur dan larva cacing yang dapat menyebabkan penyebaran penyakit kecacingan terhadap manusia (Jusuf, 2013).

Meskipun penyakit kecacingan tersebar luas disemua daerah pedesaan maupun perkotaan dengan prevalensi yang tinggi dan memberikan dampak yang besar terhadap kualitas sumber daya manusia, tetapi perhatian masyarakat terlalu kecil dan kecacingan dianggap bukan masalah kesehatan yang perlu diperhatikan. Infeksi Soil Transmitted Helminth (STH) ini termasuk dalam 11 dari 20 penyakit tropis terabaikan yang ada di Indonesia (Kemenkes RI, 2013).

\section{Metode Penelitian}

Penelitian ini menggunakan metode observasi deskriptif. Pengambilan sampel dalam penelitian ini dengan cara purposive sampling dimana pengambilan sampel didasarkan pada pertimbangan tertentu yang dibuat oleh peneliti sendiri dan sampel sesuai dengan kriteria yang diteliti (Notoatmodjo, 2005). Besar sampel pada penelitian ini menggunakan rumus Slovin (Riduwan, 2005) dengan batas toleransi kesalahan 5\% atau 0,05 sehingga diperoleh jumlah sampel 28 responden.

Sampel diperiksa dengan metode langsung yaitu menggunakan pewarna Eosin 2\%. Data yang diperoleh dianalisis secara deskriptif dengan menghitung persentase jumlah parasit nematoda usus golongan STH dengan hasil pemeriksaan yang positif untuk masing-masing jenis nematoda usus yang termasuk dalam golongan STH. 


\section{Hasil Penelitian}

Tabel 4.1 Hasil pemeriksaan dan persentase infeksi kecacingan nematode usus pada petani sayur sawi hijau di Desa Bug-bug Kecamatan Lingsar Kabupaten Lombok Barat.

\begin{tabular}{c|c|c|c|c|c}
\hline \multirow{2}{*}{ No } & Jumlah Sampel & \multicolumn{3}{|c}{ Hasil Pemeriksaan } \\
\hline \multirow{2}{*}{1} & \multirow{2}{*}{28} & Positif & Persentase & Negatif & Persentase \\
\cline { 2 - 5 } & & 2 & $7,14 \%$ & 26 & $92,86 \%$ \\
\hline
\end{tabular}

Berdasarkan tabel 4.1 diatas, hasil pemeriksaan infeksi kecacingan pada petani sayur sawi hijau diperoleh hasil 2 petani positif terinfeksi kecacingan nematoda usus dengan ditemukannya telur cacing Trichuris trichiura dengan persentase $7,14 \%$ sedangkan pada sampel lainnya tidak ditemukan adanya nematoda usus atau negatif dengan persentase $92,86 \%$. Sehingga 26 dari 28 petani sayur sawi hijau tidak terinfeksi kecacingan.

\section{Pembahasan}

Kecacingan merupakan masuknya parasit berupa cacing ke dalam tubuh manusia. Cacing di dalam usus disebut juga nematoda usus. Diantara nematoda usus terdapat sejumlah spesies yang ditularkan melalui tanah disebut juga Soil Transmitted Helminth. Spesies cacing ini mengalami proses pematangan atau menjadi infektif di tanah.

Penelitian ini membahas tentang gambaran infeksi kecacingan nematoda usus yang ditularkan melalui tanah (Soil Transmitted Helminth) pada petani sayur sawi hijau di Desa Bug-bug Kecamatan Lingsar Kabupaten Lombok Barat. Selain itu dilakukan identifikasi tentang infeksi kecacingan yang disebabkan oleh nematoda usus pada petani sayur sawi hijau.

Penularan atau proses infeksi kecacingan melalui tanah menyebabkan pekerjaan sebagai petani menjadi salah satu penyebab terjadinya infeksi kecacingan. Petani sayur sawi hijau selalu melakukan kontak langsung dengan tanah dan dalam proses bertani, petani sayur sawi hijau menggunakan pupuk kandang yang berasal dari kotoran hewan.

Berdasarkan tabel 4.1 hasil pemeriksaan infeksi kecacingan nematoda usus yang ditularkan melalui tanah pada petani sayur sawi hijau di Desa Bug-bug Kecamatan Lingsar kabupaten Lombok Barat yaitu dari 28 petani ditemukan 2 petani yang positif terinfeksi kecacingan nematoda usus dengan ditemukannya telur cacing nematoda usus spesies Trichuris trichiura sehingga diperoleh persentase infeksi Trikuriasis sebesar $7,14 \%$ pada petani sayur sawi hijau.

Penyebaran Trikuriasis disebabkan oleh kontaminasi tanah dengan tinja atau kotoran. Telur Trichiuris trichiura tumbuh di tanah yang liat, lembap dan teduh dengan suhu optimum $30^{\circ} \mathrm{C}$. Pemakaian tinja atau kotoran sebagai pupuk merupakan sumber infeksi utama dalam kasus infeksi Trikuriasis.

Ditemukan telur cacing Trichuris trichiura pada sampel feses petani sayur sawi hijau dikarenakan petani sayur sawi hijau hampir setiap hari berkontak langsung dengan tanah dimana tanah yang digunakan dalam bertani sayur sawi hijau menggunakan pupuk kandang yang berasal dari tinja atau kotoran hewan. Ketika dilakukan proses pemupukan, petani sayur sawi hijau akan bersentuhan langsung dengan pupuk tanpa menggunakan alat pelindung diri.

Beberapa petani sayur sawi hijau lebih sering mencuci tangan mereka setelah bekerja di sungai tanpa menggunakan sabun. Ditambah dengan kebiasaan makan langsung menggunakan tangan yang sebelumnya hanya dicuci dengan air sungai tanpa menggunakan sabun menjadi salah satu peluang adanya infeksi kecacingan pada petani sayur sawi hijau.

Hal tersebut mengakibatkan terdapat sisa tanah dan pupuk yang tertinggal ataupun menempel pada permukaan kulit tangan maupun kuku dari petani sayur sawi hijau yang kemudian akan masuk kedalam tubuh bersamaan dengan makanan dan minuman. Melalui makanan yang terkontaminasi masuk kedalam usus 
halus dan di dalam usus halus dinding telur akan pecah dan larva keluar menuju sekum lalu berubah menjadi cacing dewasa (Soedarto, 2011).

Sayur sawi hijau merupakan salah satu jenis sayur yang banyak diminati masyarakat. Pertumbuhan sayur sawi hijau yang tidak mengenal musim menjadi salah satu alasan sayur sawi hijau termasuk jenis sayur yang paling sering dijumpai di pasar dan menjadi sayur yang paling banyak dikonsumsi oleh masyarakat. Sayur sawi hijau tumbuh dengan mudah tanpa harus menggunakan berbagai macam pupuk kimia sehingga para petani sayur sawi hijau lebih banyak menggunakan pupuk kandang.

Masyarakat sebagai konsumen lebih banyak meminati sayuran alami yang hanya menggunkaan pupuk organik dibanding dengan sayur yang menggunakan berbagai macam pupuk berbahan kimia. Sehinga sayur sawi hijau menjadi salah satu sayur yang paling banyak dijual di pasar. Sayur sawi hijau mudah tumbuh dengan baik hanya dengan pupuk kandang dan tidak diperlukan perlakuan khusus. Menjaga kelembapan tanah dan hama serta gulma agar tidak mengganggu tumbuhan sayur sawi sehingga tidak dibutuhkan biaya yang banyak untuk bertani sayur sawi hijau. Hal tersebut menjadi salah satu alasan banyaknya petani sayur yang memilih untuk menanam sayur sawi hijau.

Seorang petani sayur sawi hijau dalam sehari dapat menghabiskan waktu 8 - 10 jam perhari di lahan pertanian sayur sawi hijau. Petani sayur sawi hijau melakukan pembersihan tumbuhan liar yang tumbuh di lahan pertanian sayur sawi hijau agar pertumbuhan sayur sawi hijau tidak terganggu. Selama proses pembersihan tumbuhan hama, para petani sayur sawi hijau tidak menggunakan alat pelindung diri deperti sarung tangan ataupun alas kaki. Seharian berkontak langsung dengan tanah dapat menyebabkan terjadinya infeksi kecacingan oleh namatoda usus yang ditularkan melalui tanah.

Tanah pertanian yang bercampur dengan pupuk kandang dan suhu tanah yang lembab menjadi tempat yang baik untuk telur cacing yang membutuhkan media tanah sebagai tempat pematangan telur menjadi telur infektif. Selain itu, air yang digunakan untuk pengairan lahan bertani sayur sawi hijau berasal dari sungai yang juga digunakan untuk masyarakat melakukan kegiatan sehari-hari seperti mandi, mencuci dan defekasi.

Dengan kebiasaan atau perilaku hidup petani sayur sawi hijau yang sebagian besar dalam sehari menghabiskan waktu di lahan bertani sayur sawi hijau dan setelah beraktivitas di lahan pertanian sayur sawi hijau, para petani tidak membersihkan diri dengan baik termasuk mencuci tangan dengan sabun sebelum makan menjadi peluang besar terjadinya infeksi dari telur cacing yang menempel pada jari dan sela-sela kuku petani sayur sawi hijau tersebut.

Petani sayur sawi hijau yang tidak terinfeksi kecacingan nematode usus yang ditularkan mealui tanah (Soil Transmitted Helminth) berjumlah 26 orang dengan persentase 92,86\%. Petani sayur sawi hjau yang tidak terinfeksi dikarenakan mereka melakukan kegiatan cuci tangan di rumah menggunakan sabun stelah melakukan kegiatan bertani. Penyakit kecacingan dapat dipicu dengan kegiatan yang dilakukan sehari-hari, sanitasi lingkungan, sanitasi personal, dan makanan yang terkontaminasi oleh telur cacing.

\section{Kesimpulan}

Berdasarkan data yang diperoleh pada penelitian gambaran infeksi kecacingan nematode usus yang ditularkan melalui tanah (Soil Transmitted Helminth) pada petani sayur sawi hijau di Desa Bug-bug Kecamatan Lingsar Kabupaten Lombok Barat, dengan jumlah sampel 28 responden disimpulkan bahwa hasil pemeriksaan feses pada petani sayur sawi hijau di Desa Bug-bug Kecamatan Lingsar Kabupaten Lombok Barat adalah telur cacing Trichuris trichiura. Petani sayur sawi hijau yang positif terinfeksi cacing Trichuris trichiura adalah $7,14 \%$.

\section{Referensi}

Akhsin Zulkoni. 2010. Parasitologi. Nuha Medika : Yogyakarta.

Ali Rafiqi Ulfa, dkk. 2016. Hubungan Personal Hygiene dan Sanitasi Lingkungan dengan Angka Kejadian Kecacingan (Soil Transmitted Helminth) pada Petani Sayur di Kelurahan Maharatu Kecamatan Marpoyan Damai Kota Pekanbaru. Pekanbaru.

BPN NTB. 2016. Kabupaten Lombok Barat Dalam Angka. Mataram. 
ISSN: 2656-2456 (Online)

ISSN: 2356-4075 (Print)

Jusuf. 2013. Gambaran Nilai Hematokrit Dengan Menggunakan Metode Mikro pada Buruh Tani Di Desa Kandat Kabupaten Kediri. Institut Ilmu Kesehatan Bhakti Wiyata Kediri. Kediri.

Kementrian kesehatan Republik Indonesia. 2013. Profil Pengendalian Penyait dan Penyehatan Lingkungan Tahun 2012. Direktorat Jenderal PP7PL : Jakarta.

Notoatmodjo Soekidjo. 2005. Metodologi Penelitian Kesehatan. Rineka Citra Putra: Jakarta.

Riduwan. 2005. Rumus dan Data dalam Aplikasi Statistika. Alfabeta:Bandung.

Safar. 2009. Parasitologi Kedokteran : Protozoologi Helmintologi Entomologi. Yrama Widya. Bandung.

Salim M. 2013. Faktor-faktor yang Berhubungan Dengan Positif Cacing Soil Transmitted Helminth (STH) Pada Petani Pengguna Pupuk Kandang Di Desa Rasau Jaya Umum Tahun 2013. Pontianak.

Soedarto. 2010. Buku Ajar Parasitologi Kedokteran : Handbook of Medical Parasitology. Sugeng Seto:Jakarta. 